\title{
Human rights and global health emergencies preparedness
}

\section{Andrea Boggio}

Department of History and Social Sciences, Bryant University, Smithfield, Rhode Island, USA

The COVS-19 has shown the limits of responses to global health emergencies that focus on emergency handling and planning.
Whe spread of infectious disease is always ranked high as a global threat. It features prominently among the list of urgent health challenges for the next decade, issued in early January 2020 by WHO [1]. The emergence of the 2019 Novel Coronavirus (COVID-19) in the Hubei Province in China, is a reminder of global health vulnerabilities.

Since the 2002-03 SARS outbreak, the global health community has engaged in substantial efforts to be prepared to handle outbreaks such as the ongoing COVID-19 outbreak. A milestone achievement is the International Health Regulations, a binding instrument of international law that entered into force on 15 June 2007 intending to assist countries to work together to save lives and livelihoods endangered by the international spread of diseases. The Regulations target the response to the international spread of disease as well as the core surveillance and response capacities of countries. Additionally, they give certain powers to State Parties (ie, closing ports, airports, and ground crossings) that governments cannot ordinarily exercise. Yet, these powers must be exercised with caution, in accordance with their relevant national law and obligations under international law, including human rights law, and upon considering scientific principles, available scientific evidence of a risk to human health, and WHO's guidance or advice [2]. As Habibi and colleagues point out, the intention of the Regulations is that "countries should not take needless measures that harm people or that disincentivise countries from reporting new risks to international public health authorities" [3].

Yet, even when done correctly, in line with the scientific knowledge, and full respect of international human rights law, emergency handling and planning is not sufficient to manage the spread of infectious disease. To be effective, emergency handling and planning must be carried out in an environment in which new treatments - such as drugs and vaccines developed ad hoc to stop the outbreak - can be developed rapidly and delivered efficiently to all persons affected. This was not the case in the urban area of Wuhan, which suffered from health care delivery problems at the time of the outbreak. In a matter of days, the local authorities conclude that the health care facilities were insufficient to handle the emergency and announced plans to build from scratch not one but two new hospitals. These construction projects were completed in just a few days and accommodate 2300 patients. Similar problems are experienced by other nations as COVID-19 spreads.

This is extraordinary. But it should not be. Strengthening the health care infrastructure should have been planned for a while. The failure to do so is a cautionary tale of insufficient efforts to protect global health. The global health community must thus push countries harder to keep strengthening their research capacity and basic health care infrastructure along with emergency handling and planning efforts. Human rights play a key told in pushing countries hard. They are a powerful tool to act as they create legal obligations that go beyond the immediate and pressing needs of emergency preparedness and handling. International human rights law is critical as it transforms global health best practices in legal duties. 
Strengthening their research capacity and basic health care infrastructure must be incorporated in epidemic preparedness.

Human rights law provides the necessary legal support to hold countries accountable for these efforts.

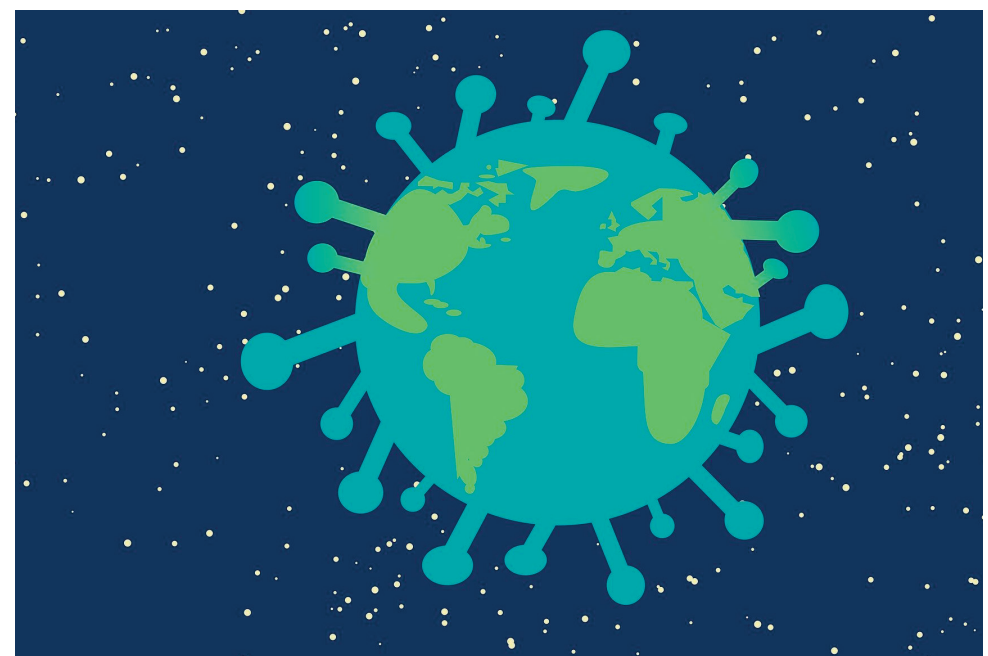

Photo: Image by Miroslava Chrienova from Pixabay.

the Covenant. In fact, the draft that was made public makes the case. It stresses that governments have "a positive duty to actively promote the advancement of science" and must fund basic and applied research (para. 50). To this, it adopts the recommendation of the Scientific Advisory Board of the United Nations [7] that "all countries, including the poorest, to invest at least 1\% of their GDP on research and urged the most advanced countries to spend at least 3\% of their GDP on research and development" (para. 51). Furthermore, it states that governments must approve "policies and regulations which foster scientific research, allocating appropriate resources in the budgets and, in general, creating an enabling and participatory environment for the conservation, development and diffusion of science and technology" (para. 50)

The General Comment on science and economic, social and cultural rights is an important addition to the human rights that are traditionally invoked in the global health arena. Most importantly, it reinforces the power of human rights law to frame the global health discourse not only in terms of public health necessity to act but also in terms of a legal duty to act. The global health community should not forget that ensuring good science and the attainment of the highest level of health are human rights and an indispensable dimension of global health policy. Only when cultivated and guaranteed as a human right, science provides the support needed to fight global health emergencies.

Funding: None.

Authorship contributions: $\mathrm{AB}$ is the sole author.

Competing interests: The author has completed the ICMJE form (available upon request from the corresponding author), and declares no conflict of interest. 
1 World Health Organization. Urgent health challenges for the next decade. 2020. Available: https://www.who.int/newsroom/photo-story/photo-story-detail/urgent-health-challenges-for-the-next-decade. Accessed: 30 March 2020.

2 World Health Assembly. International Health Regulations (2005). Geneva: World Health Organization; 2006.

3 Habibi R, Burci GL, de Campos TC, Chirwa D, Cinà M, Dagron S, et al. Do not violate the International Health Regulations during the COVID-19 outbreak. Lancet. 2020;395:664-6. Medline:32061311 doi:10.1016/S0140-6736(20)30373-1

4 UN General Assembly. International Covenant on Economic, Social and Cultural Rights. United Nations. Treaty Series. 1966;993:3.

5 Frick M. Funding for tuberculosis research—an urgent crisis of political will, human rights, and global solidarity. Int J Infect Dis. 2017;56:21-4. Medline:27919779 doi:10.1016/j.ijid.2016.11.412

6 UN Committee on Economic Social and Cultural Rights. Draft General Comment. Science and economic, social and cultural rights Art. 15: 15.1.b, 15.2, 15.3 and 15.4. 2020

7 Scientific Advisory Board of the United Nations Secretary-General. The Future of Scientific Advice to the United Nations, A Summary Report to the Secretary-General of the United Nations from the Scientific Advisory Board. UNESCO; 2016.

\section{Correspondence to:}

Andrea Boggio, JSD

Department of History and Social Sciences

Bryant University

1150 Douglas Pike

Smithfield

Rhode Island, 02917

USA

aboggio@bryant.edu 